Published on Reviews in History (https://reviews.history.ac.uk)

\title{
INTERVIEW: Claire Tomalin talks to Daniel Snowman
}

Review Number: 1602

Publish date: Thursday, 29 May, 2014

Author: Claire Tomalin

ISBN: 9780141036939

Date of Publication: 2011

Price: $£ 9.99$

Pages: 576pp.

Publisher: Penguin

Publisher url:

Place of Publication: London

Reviewer: Daniel Snowman

In the latest of our occasional Reviews in History podcast series, Daniel Snowman talks to Claire Tomalin about her work as a historical biographer.

Claire Tomalin (born Claire Delavenay on 20 June 1933) is an English author and journalist, known for her biographies on Charles Dickens, Thomas Hardy, Samuel Pepys, Jane Austen, and Mary Wollstonecraft.

Daniel Snowman is a writer, lecturer and broadcaster on social and cultural history.

You can listen to a short version of the interview here [2], or alternatively the full conversation is available here [3].

Source URL:https://reviews.history.ac.uk/review/1602

Links

[1] https://reviews.history.ac.uk/item/106633

[2] http://podcast.ulcc.ac.uk/accounts/SAScasts/ReviewsinHistory/Claire_Tomalin_interview_short.mp3

[3] http://podcast.ulcc.ac.uk/accounts/SAScasts/ReviewsinHistory/Claire_Tomalin_interview_long.mp3 